\title{
Pgrw-closed map in a Topological Space
}

\author{
R. S. Wali ${ }^{1}$ and Vijayakumari T. Chilakwad ${ }^{2}$ \\ ${ }^{I}$ Department of Mathematics, Bandari \& Rathi, College, Guledgudd, Bagalkot, Karnataka State, India \\ ${ }^{2}$ Department of Mathematics, Government First Grade College, Dharwad, Karnataka State, India
}

\begin{abstract}
The aim of this paper is to introduce pgrw-closed maps and pgrw*-closed maps and to obtain some of their properties. In section 3 pgrw-closed map is defined and compared with other closed maps. In section 4 composition of pgrw-maps is studied. In section 5 pgrw*-closed maps are defined.
\end{abstract}

Keywords: pgrw-closed set, pgrw-closed maps, pgrw*-closed maps.

\section{Introduction}

Different mathematicians worked on different versions of generalized closed maps and related topological properties. Generalized closed mappings were introduced and studied by Malghan [1]. wg-closed maps and rwg-closed maps were introduced and studied by Nagaveni [2]. Regular closed maps, gpr-closed maps and rw-closed maps were introduced and studied by Long [3], Gnanambal [4] and S. S. Benchallli [5] respectively.

\section{Preliminaries}

Throughout this paper, $(\mathrm{X}, \tau)$ and $(\mathrm{Y}, \sigma)$ (or simply $\mathrm{X}$ and $\mathrm{Y}$ ) represent the topological spaces. For a subset $\mathrm{A}$ of a space $\mathrm{X}, \operatorname{cl}(\mathrm{A})$ and $\operatorname{int}(\mathrm{A})$ denote the closure of $\mathrm{A}$ and the interior of $\mathrm{A}$ respectively. $\mathrm{X} \backslash \mathrm{A}$ or $\mathrm{A}^{\mathrm{c}}$ denotes the complement of A in X.

We recall the following definitions and results.

\section{Definition 2.1}

A subset $\mathrm{A}$ of a topological space $(\mathrm{X}, \tau)$ is called

1. a semi-open set[6] if $\mathrm{A} \subseteq \operatorname{cl}(\operatorname{int}(\mathrm{A}))$ and a semi-closed set if $\operatorname{int}(\mathrm{cl}(\mathrm{A})) \subseteq \mathrm{A}$.

2. a pre-open set[7] if $\mathrm{A} \subseteq \operatorname{int}(\mathrm{cl}(\mathrm{A}))$ and a pre-closed set if $\operatorname{cl}(\operatorname{int}(\mathrm{A})) \subseteq \mathrm{A}$.

3. an $\alpha$-open set [8]if $\mathrm{A} \subseteq \operatorname{int}(\operatorname{cl}(\operatorname{int}(\mathrm{A})))$ and an $\alpha$-closed set if $\operatorname{cl}(\operatorname{int}(\operatorname{cl}(\mathrm{A}))) \subseteq \mathrm{A}$.

4. a semi-pre open set $[9](=\beta$-open)[10] if $\mathrm{A} \subseteq \operatorname{cl}(\operatorname{int}(\mathrm{cl}(\mathrm{A})))$ and a semi-pre closed set $(=\beta$-closed) if $\operatorname{int}(\operatorname{cl}(\operatorname{int}(\mathrm{A}))) \subseteq \mathrm{A}$.

5. a regular open set [10] if $\mathrm{A}=\operatorname{int}(\mathrm{clA}))$ and a regular closed set if $\mathrm{A}=\mathrm{cl}(\mathrm{int}(\mathrm{A}))$.

6. $\delta$-closed [11] if $A=\operatorname{cl} \delta(A)$, where $\operatorname{cl} \delta(A)=\{x \in X: \operatorname{int}(\operatorname{cl}(U)) \cap A \neq \Phi, U \in \tau$ and $x \in U\}$

7. a regular semi open [12] set if there is a regular open set $\mathrm{U}$ such that $\mathrm{U} \subseteq \mathrm{A} \subseteq \mathrm{cl}(\mathrm{U})$.

8. a regular $\alpha$-closed set (briefly, r $\alpha$-closed)[13] if there is a regular closed set $\mathrm{U}$ such that $\mathrm{U} \subset \mathrm{A} \subset \alpha \mathrm{cl}(\mathrm{U})$.

9. a generalized closed set (briefly g-closed)[14] if $\mathrm{cl}(\mathrm{A}) \subseteq \mathrm{U}$ whenever $\mathrm{A} \subseteq \mathrm{U}$ and $\mathrm{U}$ is open in $\mathrm{X}$.

10. a regular generalized closed set(briefly rg-closed)[15] if $\operatorname{cl}(\mathrm{A}) \subseteq \mathrm{U}$ whenever $\mathrm{A} \subseteq \mathrm{U}$ and $\mathrm{U}$ is regular open in $\mathrm{X}$.

12. a generalized pre regular closed set(briefly gpr-closed)[4] if $\operatorname{pcl}(\mathrm{A}) \subseteq \mathrm{U}$ whenever $\mathrm{A} \subseteq \mathrm{U}$ and $\mathrm{U}$ is regular open in X.

13. a generalized semi-pre closed set(briefly gsp-closed)[16] if $\operatorname{spcl}(\mathrm{A}) \subseteq \mathrm{U}$ whenever $\mathrm{A} \subseteq \mathrm{U}$ and $\mathrm{U}$ is open in $\mathrm{X}$. 14. a w-closed set [17] if $\operatorname{cl}(\mathrm{A}) \subseteq \mathrm{U}$ whenever $\mathrm{A} \subseteq \mathrm{U}$ and $\mathrm{U}$ is semi-open in $\mathrm{X}$.

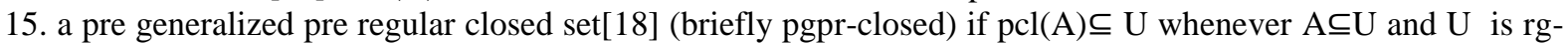
open in $\mathrm{X}$.

16. a generalized semi pre regular closed (briefly gspr-closed) set [19] if $\operatorname{spcl}(\mathrm{A}) \subseteq \mathrm{U}$ whenever $\mathrm{A} \subseteq \mathrm{U}$ and $\mathrm{U}$ is regular open in X.

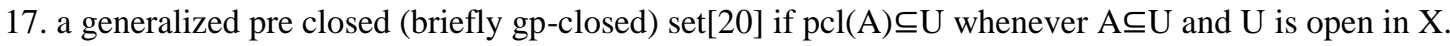

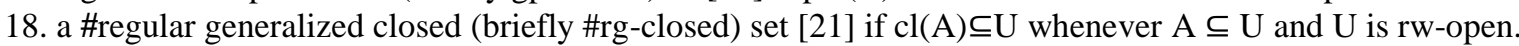

19. a g*s-closed [22]set if scl $(\mathrm{A}) \subseteq \mathrm{U}$ whenever $\mathrm{A} \subseteq \mathrm{U}$ and $\mathrm{U}$ is gs open.

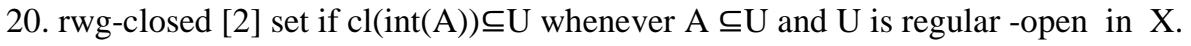

21. a rw-closed [5] if $\operatorname{cl}(\mathrm{A}) \subseteq \mathrm{U}$ whenever $\mathrm{A} \subseteq \mathrm{U}$ and $\mathrm{U}$ is regular semi-open in $\mathrm{X}$.

22. $\alpha$ g-closed[23] if $\alpha \mathrm{cl}(\mathrm{A}) \subseteq \mathrm{U}$ whenever $\mathrm{A} \subseteq \mathrm{U}$ and $\mathrm{U}$ is open in $\mathrm{X}$.

23. a $\omega \alpha$-closed set[24] if $\alpha \mathrm{cl}(\mathrm{A}) \subseteq \mathrm{U}$ whenever $\mathrm{A} \subseteq \mathrm{U}$ and $\mathrm{U}$ is $\omega$-open in $\mathrm{X}$.

24. an $\alpha$-regular w closed set(briefly arw -closed)[25] if $\alpha c l(A) \subseteq U$ whenever $A \subseteq U$ and $\mathrm{U}$ is rw-open in $\mathrm{X}$.

The complements of the above mentioned closed sets are the respective open sets. 
Definition 2.2

A map $\mathrm{f}:(\mathrm{X}, \tau) \rightarrow(\mathrm{Y}, \sigma)$ is said to be

1. $\alpha$-closed [8] if $\mathrm{f}(\mathrm{F})$ is $\alpha$-closed in $Y$ for every closed subset $F$ of $X$.

2. $\alpha$ g-closed [23] if $\mathrm{f}(\mathrm{F})$ is $\alpha \mathrm{g}$-closed in $\mathrm{Y}$ for every closed subset $\mathrm{F}$ of $\mathrm{X}$.

4. rwg-closed [2] if $\mathrm{f}(\mathrm{V})$ is rwg-closed in $\mathrm{Y}$ for every closed subset $\mathrm{V}$ of $\mathrm{X}$.

6. gp-closed [20] if $f(V)$ is gp-closed in $Y$ for every closed subset $V$ of $X$.

7. gpr-closed[4] if $f(V)$ is gpr-closed in $Y$ for every closed subset $V$ of $X$.

8. $\omega \alpha$-closed [24] if $f(V)$ is $\omega \alpha$-closed in $Y$ for every closed subset $V$ of $X$.

9. gspr-closed [19]if $\mathrm{f}(\mathrm{V})$ is gspr-closed in $\mathrm{Y}$ for every closed subset V of X.

10. $\omega$-closed [17] if $f(V)$ is $\omega$-closed in Y for every closed subset $V$ of $X$.

11. $r \omega$-closed [5] if $f(V)$ is rw-closed in Y for every closed subset $V$ of $X$.

12. regular-closed if $f(F)$ is closed in Yfor every regular closed set $F$ of $X$.

13. $g *$ s-closed [22 ]map if for each closed set $F$ in $X, f(F)$ is a $g^{*} s$-closed in $y$.

14. $\alpha r \omega$-closed [25 ] if the image of every closed set in $(\mathrm{X}, \tau)$ is $\alpha \mathrm{r} \omega$-closed in $(\mathrm{Y}, \sigma)$.

15. pre-closed [26 ] if $\mathrm{f}(\mathrm{V})$ is pre-closed in $\mathrm{Y}$ for every closed set $\mathrm{V}$ of $\mathrm{X}$.

16. $\delta$-closed $[11$ ] if for every closed set $\mathrm{G}$ in $\mathrm{X}, \mathrm{f}(\mathrm{G})$ is a $\delta$-closed set in $\mathrm{Y}$.

17. \#rg-closed [21] if $f(F)$ is \#rg-closed in $(Y, \sigma)$ for every \#rg-closed set $F$ of $(X, \tau)$.

18. gsp-closed [16] if $f(V)$ is gsp-closed in $(Y, \sigma)$ for every closed set $\mathrm{V}$ of $(X, \tau)$.

19. semi-closed [27] if image of every closed subset of $X$ is semi-closed in $Y$.

20. Contra-closed [28] if $f(F)$ is open in $Y$ for every closed set $F$ of $X$.

21. Contra regular-closed if $\mathrm{f}(\mathrm{F})$ is $r$-open in $Y$ for every closed set $F$ of $X$.

22. Contra semi-closed [29] if $f(F)$ is s-open in $Y$ for every closed set $F$ of $X$.

23. Semi pre-closed [30] ( Beta-closed) if $f(V)$ is semi-pre-closed in $Y$ for every closed subset $V$ of $X$.

24. g-closed [14] if $f(V)$ is g-closed in $Y$ for every closed subset V of $X$.

25. r $\alpha$-closed [13] if $f(V)$ is r $\alpha$-closed in $Y$ for every closed subset $V$ of $X$.

The following results are from [31]

Theorem: Every pgpr-closed set is pgrw-closed.

Theorem: A pre-closed set is pgrw-closed.

Corollary: Every $\alpha$ - closed set is pgrw- closed.

Corollary: Every closed set is pgrw-closed.

Corollary: Every regular closed set is pgrw-closed.

Corollary: Every $\delta$ - closed set is pgrw- closed.

Theorem: Every \#rg- closed set is pgrw- closed.

Theorem: Every arw-closed set is pgrw-closed.

Theorem: Every pgrw-closed set is gp-closed

Theorem: Every pgrw- closed set is gsp-closed.

Corollary: Every pgrw- closed set is gspr- closed.

Corollary: Every pgrw- closed set is gpr- closed.

Theorem: If A is regular open and pgrw-closed, then A is pre-closed.

Theorem: If A is open and gp-closed, then A is pgrw-closed.

Theorem: If A is both open and g-closed, then A is pgrw -closed.

Theorem: If A is regular-open and gpr-closed, then it is pgrw-closed.

Theorem: If A is both semi-open and w-closed, then it is pgrw-closed.

Theorem: If $\mathrm{A}$ is open and $\alpha \mathrm{g}$-closed, then it is pgrw -closed.

\section{Pgrw-CLOSED MAP}

Definition 3.1: A map $\mathrm{f}:(\mathrm{X},, \tau) \rightarrow(\mathrm{Y}, \sigma)$ is said to be a pre generalized regular weakly-closed map(pgrwclosed map) if the image of every closed set in $(\mathrm{X}, \tau)$ is pgrw-closed in $(\mathrm{Y}, \sigma)$.

Example 3.2: $X=\{a, b, c\}, \tau=\{X, \phi,\{a\}\}$ and $Y=\{a, b, c\}, \sigma=\{Y, \phi,\{a\},\{b, c\}\}$.

Closed sets in $X$ are $X, \phi,\{b, c\}$. pgrw-closed sets in $Y$ are $Y, \phi,\{a\},\{b\},\{c\},\{a, b\},\{a, c\},\{b, c\}$.

A map $f: X \rightarrow Y$ is defined by $f(a)=b, f(b)=c, f(c)=a$. Image of every closed set in $X$ is pgrw-closed in $Y$. So $f$ is a pgrw-closed map.

Theorem 3.3: Every closed map is a pgrw-closed map.

Proof: $f:(X, \tau) \rightarrow(Y, \sigma)$ is a closed map.

$\Rightarrow \forall$ closed set $\mathrm{A}$ in $\mathrm{X}$ f(A) is closed in $\mathrm{Y}$.

$\Rightarrow \forall$ closed set $\mathrm{A}$ in $\mathrm{X}$ f(A) is pgrw- closed in $\mathrm{Y}$.

$\Rightarrow \mathrm{f}$ is a pgrw-closed map.

The converse is not true. 
Example: 3.4:In the example $3.2 \mathrm{f}$ is a pgrw-closed map and as $\{b, c\}$ is closed in $X$ and $f(\{b, c\})=\{a, c\}$ is not closed in $\mathrm{Y}, \mathrm{f}$ is not a closed map.

Theorem 3.5: Every pre-closed (regular-closed, $\alpha$-closed, $\delta$-closed ,\#rg-closed, pgpr-closed, $\alpha$ rw-closed) map is pgrw-closed.

Proof: $f:(X, \tau) \rightarrow(Y, \sigma)$ is a pre-closed map.

$\Rightarrow \forall$ closed set $\mathrm{A}$ in $\mathrm{X} \mathrm{f}(\mathrm{A})$ is pre- closed in $\mathrm{Y}$.

$\Rightarrow \forall$ closed set $\mathrm{A}$ in $\mathrm{X} \mathrm{f}(\mathrm{A})$ is pgrw- closed in $\mathrm{Y}$.

$\Rightarrow \mathrm{f}$ is a pgrw-closed map.

Similarly remaining statements can be proved.

The converse is not true.

Example 3.6: $\mathrm{X}=\{\mathrm{a}, \mathrm{b}, \mathrm{c}\}, \tau=\{\mathrm{X}, \phi,\{\mathrm{a}\},\{\mathrm{b}\},\{\mathrm{a}, \mathrm{b}\}\}$ and $\mathrm{Y}=\{\mathrm{a}, \mathrm{b}, \mathrm{c}, \mathrm{d}\}, \sigma=\{\mathrm{Y}, \phi,\{\mathrm{a}\},\{\mathrm{b}\},\{\mathrm{a}, \mathrm{b}\},\{\mathrm{a}, \mathrm{b}, \mathrm{c}\}\}$.

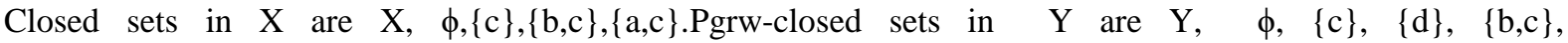
$\{c, d\},\{a, d\},\{b, d\},\{b, c, d\},\{a, c, d\},\{a, b, d\}$. Pre-closed sets in $Y$ are $Y, \phi,\{c\},\{d\},\{c, d\},\{a, c, d\},\{b, c, d\} . p g p r-$ closed sets in $\mathrm{Y}$ are $\mathrm{Y}, \phi,\{\mathrm{c}\},\{\mathrm{d}\},\{\mathrm{c}, \mathrm{d}\},\{\mathrm{a}, \mathrm{c}, \mathrm{d}\},\{\mathrm{b}, \mathrm{c}, \mathrm{d}\}$. $\delta$-closed sets in $\mathrm{Y}$ are $\mathrm{Y}, \phi,\{\mathrm{c}, \mathrm{d}\},\{\mathrm{a}, \mathrm{c}, \mathrm{d}\},\{\mathrm{b}, \mathrm{c}, \mathrm{d}\}$. A map $f: X \rightarrow Y$ is defined by $f(a)=b, f(b)=c, f(c)=d$. $f$ is a pgrw-closed map. $\{a, c\}$ is closed in $X$. $f(\{a, c\})=\{b, d\}$ which is neither a pre-closed nor a pgpr-closed set. So $\mathrm{f}$ is neither a pre-closed map nor a pgpr-closed map. $\{c\}$ is closed in $X . f(\{c\})=\{d\}$ is not $\delta$-closed. So f is not a $\delta$-closed map.

Example 3.7: In the example 3.2 regular closed sets in $\mathrm{Y}$ are $\mathrm{Y}, \phi,\{\mathrm{a}\},\{\mathrm{b}, \mathrm{c}\}, \alpha$-closed sets in $\mathrm{Y}$ are $\mathrm{Y}, \phi,\{\mathrm{a}\}$, $\{b, c\}$,\#rg-closed sets in $\mathrm{Y}$ are $\mathrm{Y}, \phi,\{\mathrm{a}\},\{\mathrm{b}, \mathrm{c}\}$ and $\alpha \mathrm{rw}$-closed sets are $\mathrm{Y}, \phi,\{\mathrm{a}\},\{\mathrm{b}, \mathrm{c}\}$. $\mathrm{f}$ is a pgrw closed map, but $f(\{b, c\})=\{a, c\}$ is neither a regular closed set nor $\alpha$-closed nor \#rg-closed nor $\alpha$ r $\omega$-closed. So $f$ is neither a regular closed map nor $\alpha$-closed nor \#rg-closed nor $\alpha$ rw-closed.

Theorem 3.8: If $\mathrm{f}:(\mathrm{X}, \tau) \rightarrow(\mathrm{Y}, \sigma)$ is a contra-r-closed and pgrw-closed map, then $\mathrm{f}$ is pre-closed.

Proof: $f:(X, \tau) \rightarrow(Y, \sigma)$ is a contra-r-closed and pgrw-closed map.

$\Rightarrow \forall$ closed set $\mathrm{A}$ in $\mathrm{X} \mathrm{f}(\mathrm{A})$ is regular open and pgrw-closed in $\mathrm{Y}$.

$\Rightarrow \forall$ closed set $\mathrm{A}$ in $\mathrm{X} \mathrm{f}(\mathrm{A})$ is pre- closed in $\mathrm{Y}$.

$\Rightarrow \mathrm{f}$ is a pre-closed map.

Theorem 3.9: If $\mathrm{f}:(\mathrm{X}, \tau) \rightarrow(\mathrm{Y}, \sigma)$ is a pgrw-closed map, then $\mathrm{f}$ is a gp-closed(gsp-closed, gspr-closed, gprclosed) map.

Proof: $f:(X, \tau) \rightarrow(Y, \sigma)$ is a pgrw-closed map.

$\Rightarrow \forall$ closed set $\mathrm{A}$ in $\mathrm{X} \mathrm{f}(\mathrm{A})$ is a pgrw-closed set in $\mathrm{Y}$.

$\Rightarrow \forall$ closed set $\mathrm{A}$ in $\mathrm{X} \mathrm{f}(\mathrm{A})$ is a gp-closed set in $\mathrm{Y}$.

$\Rightarrow \mathrm{f}$ is a gp-closed map. Similarly the other results follow.

The converse is not true.

Example 3.10: $X=\{a, b, c\}, \tau=\{X, \phi,\{a\},\{b, c\}\} . Y=\{a, b, c\}, \sigma=\{Y, \phi,\{a\}\}$.

Pgrw-closed sets in $Y$ are $Y, \phi,\{b\},\{c\},\{b, c\}$. gp-closed sets in $Y$ are $, \phi,\{b\},\{c\},\{a, b\},\{b, c\},\{a, c\}$. gpr-closed sets in $Y$ are all subsets of $Y$. A map $f:(X, \tau) \rightarrow(Y, \sigma)$ is defined by $f(a)=b, f(b)=a, f(c)=c$. $f$ is gp-closed and gpr-closed. $f(\{b, c\})=\{a, c\}$ is not pgrw-closed. So $f$ is not pgrw-closed.

Example 3.11: $X=\{a, b, c, d\}, \tau=\{X, \phi,\{a\},\{b\},\{a, b\},\{a, b, c\}\}$ and $Y=\{a, b, c\}$,

$\sigma=\{\mathrm{Y}, \phi,\{\mathrm{a}\},\{\mathrm{b}\},\{\mathrm{a}, \mathrm{b}\}\}$. Closed sets in $X$ are $X, \phi,\{\mathrm{b}, \mathrm{c}, \mathrm{d}\},\{\mathrm{a}, \mathrm{c}, \mathrm{d}\},\{\mathrm{c}, \mathrm{d}\},\{\mathrm{d}\}$.

gsp-closed sets in $\mathrm{Y}$ are all subsets of $\mathrm{Y}$.gspr-closed sets in $\mathrm{Y}$ are all subsets of $\mathrm{Y}$. pgrw-closed sets in $\mathrm{Y}$ are $\mathrm{Y}$, $\phi,\{c\},\{a, c\},\{b, c\}$. A map $f: X \rightarrow Y$ is defined by $f(a)=b, f(b)=a, f(c)=c, f(d)=a$. $f$ is gsp-closed and gsprclosed, but $\mathrm{f}$ is not pgrw-closed.

Theorem 3.12: If $\mathrm{f}:(\mathrm{X}, \tau) \rightarrow(\mathrm{Y}, \sigma)$ is a contra closed and gp-closed map, then $\mathrm{f}$ is pgrw-closed.

Proof: $f:(X, \tau) \rightarrow(Y, \sigma)$ is a contra closed and gp-closed map.

$\Rightarrow \forall$ closed set $\mathrm{V}$ in $\mathrm{X} \mathrm{f}(\mathrm{V})$ is open and gp-closed in $\mathrm{Y}$.

$\Rightarrow \forall$ closed set $\mathrm{V}$ in $\mathrm{X} \mathrm{f}(\mathrm{V})$ is pgrw-closed in $\mathrm{Y}$.

$\Rightarrow \mathrm{f}$ is a pgrw-closed map.

Theorem 3.13:If $\mathrm{f}:(\mathrm{X}, \tau) \rightarrow(\mathrm{Y}, \sigma)$ is a contra-closed and $\alpha \mathrm{g}$-closed map, then $\mathrm{f}$ is pgrw-closed.

Proof: $f:(X, \tau) \rightarrow(Y, \sigma)$ is a contra closed and $\alpha \mathrm{g}$-closed map.

$\Rightarrow \forall$ closed set $\mathrm{V}$ in $\mathrm{X} \mathrm{f}(\mathrm{V})$ is open and $\alpha \mathrm{g}$-closed in $\mathrm{Y}$.

$\Rightarrow \forall$ closed set $\mathrm{V}$ in $\mathrm{X} \mathrm{f}(\mathrm{V})$ is pgrw-closed in $\mathrm{Y}$.

$\Rightarrow \mathrm{f}$ is a pgrw-closed map.

Theorem 3.14:If $\mathrm{f}:(\mathrm{X}, \tau) \rightarrow(\mathrm{Y}, \sigma)$ is a contra regular-closed and gpr-closed map, then $\mathrm{f}$ is a pgrw-closed map.

Proof: $f:(X, \tau) \rightarrow(Y, \sigma)$ is a contra regular-closed and gpr-closed map.

$\Rightarrow \forall$ closed set $\mathrm{V}$ in $\mathrm{X} \mathrm{f}(\mathrm{V})$ is regular-open and gpr-closed in $\mathrm{Y}$.

$\Rightarrow \forall$ closed set $\mathrm{V}$ in $\mathrm{X} \mathrm{f}(\mathrm{V})$ is pgrw-closed in $\mathrm{Y}$.

$\Rightarrow \mathrm{f}$ is a pgrw-closed map. 
Theorem 3.15: If $\mathrm{f:}(\mathrm{X}, \tau) \rightarrow(\mathrm{Y}, \sigma)$ is a contra semi-closed and w-closed map, then $\mathrm{f}$ is a pgrw-closed map.

Proof: $f:(X, \tau) \rightarrow(Y, \sigma)$ is a contra semi-closed and w-closed map.

$\Rightarrow \forall$ closed set $\mathrm{V}$ in $\mathrm{X} \mathrm{f}(\mathrm{V})$ is a semi-open and $\mathrm{w}$-closed set in $\mathrm{Y}$.

$\Rightarrow \forall$ closed set $\mathrm{V}$ in $\mathrm{X} \mathrm{f}(\mathrm{V})$ is pgrw-closed in $\mathrm{Y}$.

$\Rightarrow \mathrm{f}$ is a pgrw-closed map.

Theorem 3.16: If $\mathrm{f}:(\mathrm{X}, \tau) \rightarrow(\mathrm{Y}, \sigma)$ is a contra closed and g-closed map, then $\mathrm{f}$ is pgrw-closed.

Proof: $f:(X, \tau) \rightarrow(Y, \sigma)$ is a contra closed and g-closed map.

$\Rightarrow \forall$ closed set $\mathrm{V}$ in $\mathrm{X} \mathrm{f}(\mathrm{V})$ is an open and g-closed set in $\mathrm{Y}$.

$\Rightarrow \forall$ closed set $\mathrm{V}$ in $\mathrm{X} \mathrm{f}(\mathrm{V})$ is pgrw-closed in $\mathrm{Y}$.

$\Rightarrow \mathrm{f}$ is a pgrw-closed map.

The following examples illustrate that the pgrw-closed map and rw-closed map ( $\mathrm{g}^{*} \mathrm{~s}$-closed map, r $\alpha$-closed map and w $\alpha$-closed map, $\beta$-closed map, semi-closed map) are independent.

Example 3.17: To show that pgrw-closed map and rw-closed map are independent.

i) $X=\{a, b, c\}, \tau=\{X, \phi,\{a\},\{a, c\}\} . Y=\{a, b, c, d\}, \sigma=\{Y, \phi,\{a, b\},\{c, d\}$.

pgrw-closed sets in $\mathrm{Y}$ are all subsets of $\mathrm{Y}$. rw-closed sets in $\mathrm{Y}$ are $\mathrm{Y}, \phi,\{\mathrm{a}, \mathrm{b}\},\{\mathrm{c}, \mathrm{d}\}$. A map

$\mathrm{f}:(\mathrm{X}, \tau) \rightarrow(\mathrm{Y}, \sigma)$ is defined by $\mathrm{f}(\mathrm{a})=\mathrm{b}, \mathrm{f}(\mathrm{b})=\mathrm{c}, \mathrm{f}(\mathrm{c})=\mathrm{a}$. $\mathrm{f}$ is pgrw-closed, but $\mathrm{f}$ is not rw-closed.

ii) $\mathrm{X}=\{\mathrm{a}, \mathrm{b}, \mathrm{c}\}, \tau=\{\mathrm{X}, \phi,\{\mathrm{a}\}\}, \mathrm{Y}=\{\mathrm{a}, \mathrm{b}, \mathrm{c}\}, \sigma=\{\mathrm{Y}, \phi,\{\mathrm{a}\},\{\mathrm{b}\},\{\mathrm{a}, \mathrm{b}\}\}$.

pgrw-closed sets in $\mathrm{Y}$ are $\mathrm{Y}, \phi,\{\mathrm{c}\},\{\mathrm{b}, \mathrm{c}\},\{\mathrm{a}, \mathrm{c}\}$. rw-closed sets in $\mathrm{Y}$ are $\mathrm{Y}, \phi,\{\mathrm{c}\},\{\mathrm{a}, \mathrm{b}\},\{\mathrm{b}, \mathrm{c}\},\{\mathrm{a}, \mathrm{c}\}\}$. A map $f:(X, \tau) \rightarrow(Y, \sigma)$ is defined by $f(a)=c, f(b)=a, f(c)=b$. $f$ is not pgrw-closed but $f$ is rw-closed.

Example 3.18: To show that pgrw-closed map and $\mathrm{g}^{*} \mathrm{~s}$-closed map are independent.

i) $X=\{a, b, c, d\}, \tau=\{X, \phi,\{a\},\{a, c\}\} . Y=\{a, b, c\}, \sigma=\{Y, \phi,\{a\},\{b, c\}\}$.

pgrw-closed sets in $\mathrm{Y}$ are all subsets of $\mathrm{Y}$. $\mathrm{g}^{*}$ s-closed sets in $\mathrm{Y}$ are $\mathrm{Y}, \phi,\{\mathrm{a}\},\{\mathrm{b}, \mathrm{c}\}$. A map

$\mathrm{f}: \mathrm{X} \rightarrow \mathrm{Y}$ is defined by $\mathrm{f}(\mathrm{a})=\mathrm{c}, \mathrm{f}(\mathrm{b})=\mathrm{a}, \mathrm{f}(\mathrm{c})=\mathrm{b}, \mathrm{f}(\mathrm{d})=\mathrm{b}$. $\mathrm{f}$ is pgrw-closed, but $\mathrm{f}$ is not $\mathrm{g}$ *s-closed.

ii) $\mathrm{X}=\{\mathrm{a}, \mathrm{b}, \mathrm{c}, \mathrm{d}\}, \tau=\{\mathrm{X}, \phi,\{\mathrm{b}, \mathrm{c}\},\{\mathrm{b}, \mathrm{c}, \mathrm{d}\}\{\mathrm{a}, \mathrm{b}, \mathrm{c}\}\} . \mathrm{Y}=\{\mathrm{a}, \mathrm{b}, \mathrm{c}, \mathrm{d}\}, \sigma=\{\mathrm{Y}, \phi,\{\mathrm{a}\},\{\mathrm{b}\},\{\mathrm{a}, \mathrm{b}\},\{\mathrm{a}, \mathrm{b}, \mathrm{c}\}\}$. pgrwclosed sets in $\mathrm{Y}$ are $\mathrm{Y}, \phi,\{c\},\{d\},\{b, c\},\{c, d\},\{a, d\},\{b, d\},\{b, c, d\},\{a, c, d\},\{a, b, d\} . g{ }^{*}$ s-closed sets in $Y$ are $\mathrm{Y}, \phi,\{\mathrm{a}\},\{\mathrm{b}\},\{\mathrm{c}\},\{\mathrm{d}\},\{\mathrm{b}, \mathrm{c}\},\{\mathrm{c}, \mathrm{d}\},\{\mathrm{a}, \mathrm{d}\},\{\mathrm{a}, \mathrm{c}\},\{\mathrm{b}, \mathrm{c}, \mathrm{d}\},\{\mathrm{a}, \mathrm{c}, \mathrm{d}\}$. A map $\mathrm{f}: \mathrm{X} \rightarrow \mathrm{Y}$ is defined by $\mathrm{f}(\mathrm{a})=\mathrm{c}, \mathrm{f}(\mathrm{b})=\mathrm{d}$, $\mathrm{f}(\mathrm{c})=\mathrm{b}, \mathrm{f}(\mathrm{d})=a$. $\mathrm{f}$ is not pgrw-closed, but $\mathrm{f}$ is $\mathrm{g}^{*}$ s-closed.

Example 3.19: To show that pgrw-closed map and ro-closed map are independent.

i) $\mathrm{X}=\{\mathrm{a}, \mathrm{b}, \mathrm{c}\}, \tau=\{\mathrm{X}, \phi,\{\mathrm{a}\},\{\mathrm{a}, \mathrm{c}\}\}$ and $\mathrm{Y}=\{\mathrm{a}, \mathrm{b}, \mathrm{c}\}, \sigma=\{\mathrm{Y}, \phi,\{\mathrm{a}\},\{\mathrm{b}, \mathrm{c}\}\}$. Pgrw-closed sets in $\mathrm{Y}$ are $\mathrm{Y}, \phi,\{\mathrm{a}\},\{\mathrm{b}\}$, $\{c\},\{a, b\},\{b, c\},\{a, c\}$. r $\alpha$-closed sets in $Y$ are $Y, \phi,\{a\},\{b, c\}$. A map $f: X \rightarrow Y$ is defined by $f(a)=c, f(b)=a$, $\mathrm{f}(\mathrm{c})=\mathrm{b}$. $\mathrm{f}$ is a pgrw-closed map, but $\mathrm{f}$ is not r $\alpha$-closed .

ii) $X=\{a, b, c, d\}, \tau=\{X, \phi,\{a\},\{c, d\},\{a, c, d\}\} . Y=\{a, b, c, d\}, \sigma=\{Y, \phi,\{a\},\{b\},\{a, b\},\{a, b, c\}\}$. Pgrw-closed sets in $\mathrm{Y}$ areY, $\phi,\{\mathrm{c}\},\{\mathrm{d}\},\{\mathrm{b}, \mathrm{c}\},\{\mathrm{c}, \mathrm{d}\},\{\mathrm{a}, \mathrm{d}\},\{\mathrm{b}, \mathrm{d}\},\{\mathrm{b}, \mathrm{c}, \mathrm{d}\},\{\mathrm{a}, \mathrm{c}, \mathrm{d}\},\{\mathrm{a}, \mathrm{b}, \mathrm{d}\}$.

ra-closed sets in $Y$ are $Y, \phi,\{a\},\{b\},\{b, c, d\},\{a, c, d\},\{a, d\},\{b, d\},\{a, c\},\{b, c\}$.

A map $f: X \rightarrow Y$ is defined by $f(a)=c, f(b)=a, f(c)=c, f(d)=d$. $f$ is not a pgrw-closed map, but $f$ is r $\alpha$-closed.

Example 3.20: To show that pgrw-closed map and $w \alpha$-closed map are independent.

i) $X=\{a, b, c, d\}, \tau=\{X, \phi,\{a, b\},\{c, d\}\} . Y=\{a, b, c, d\} \sigma=\{Y, \phi,\{b, c\},\{b, c, d\},\{a, b, c\}\}$

Pgrw-closed sets in $\mathrm{Y}$ are $\mathrm{Y}, \phi,\{\mathrm{a}\},\{\mathrm{b}\},\{\mathrm{c}\},\{\mathrm{d}\},\{\mathrm{a}, \mathrm{b}\},\{\mathrm{a}, \mathrm{c}\},\{\mathrm{c}, \mathrm{d}\},\{\mathrm{a}, \mathrm{d}\},\{\mathrm{b}, \mathrm{d}\},\{\mathrm{a}, \mathrm{c}, \mathrm{d}\},\{\mathrm{a}, \mathrm{b}, \mathrm{d}\}$.w $\alpha$-closed sets in $Y$ are $Y, \phi,\{a\},\{d\},\{a, d\},\{a, c, d\},\{a, b, d\}$. A map $f: X \rightarrow Y$ is defined by $f(a)=a, f(b)=c, f(c)=d, f(d)=a$. $f$ is pgrw-closed, but $\mathrm{f}$ is not w $\alpha$-closed.

ii) $\mathrm{X}=\{\mathrm{a}, \mathrm{b}, \mathrm{c}\}, \tau=\{\mathrm{X}, \phi,\{\mathrm{a}\},\{\mathrm{b}\},\{\mathrm{a}, \mathrm{b}\}\} . \mathrm{Y}=\{\mathrm{a}, \mathrm{b}, \mathrm{c}, \mathrm{d}\} \sigma=\{\mathrm{Y}, \phi,\{\mathrm{a}\},\{\mathrm{b}\},\{\mathrm{a}, \mathrm{b}\},\{\mathrm{a}, \mathrm{b}, \mathrm{c}\}\}$

pgrw-closed sets in $Y$ are $Y, \phi,\{c\},\{d\},\{b, c\},,\{c, d\},\{a, d\},\{b, d\},\{b, c, d\},\{a, c, d\},\{a, b, d\}$.

$w \alpha$-closed sets in $Y$ are $Y, \phi,\{a\},\{b\},\{c\},\{a, b\},\{b, c\},\{a, c\},\{a, b, c\},\{a, b, d\}$. A map $f: X \rightarrow Y$ is defined by $f(a)=c$, $f(b)=a, f(c)=b . f$ is not pgrw-closed, but w $\alpha$-closed.

Example 3.21: To show that pgrw-closed map and $\beta$-closed map are independent.

i) $X=\{a, b, c, d\}, \sigma=\{X, \phi,\{a\},\{b\},\{a, b\},\{a, b, c\}\}$ and $Y=\{a, b, c, d\}, \sigma=\{Y, \phi,\{a\},\{b\},\{a, b\},\{a, b, c\}\}$ pgrw-closed sets in $\mathrm{Y}$ are $\mathrm{Y}, \phi,\{\mathrm{c}\},\{\mathrm{d}\},\{\mathrm{b}, \mathrm{c}\},\{\mathrm{c}, \mathrm{d}\},\{\mathrm{a}, \mathrm{d}\},\{\mathrm{b}, \mathrm{d}\},\{\mathrm{b}, \mathrm{c}, \mathrm{d}\},\{\mathrm{a}, \mathrm{c}, \mathrm{d}\},\{\mathrm{a}, \mathrm{b}, \mathrm{d}\} . \beta$-closed sets in $\mathrm{Y}$ are $\mathrm{Y}, \phi$, $,\{a\},\{b\},\{c\},\{d\},\{b, c\},\{a, c\},\{b, d\},\{c, d\},\{a, d\},\{b, c, d\},\{a, c, d\}$. A map $f: X \rightarrow Y$ is defined by $f(a)=b, f(b)=a$, $\mathrm{f}(\mathrm{c})=\mathrm{b}, \mathrm{f}(\mathrm{d})=\mathrm{d}$. $\mathrm{f}$ is pgrw-closed map, but not $\beta$-closed.

ii) A map $\mathrm{f}: \mathrm{X} \rightarrow \mathrm{Y}$ is defined by $\mathrm{f}(\mathrm{a})=\mathrm{c}, \mathrm{f}(\mathrm{b})=\mathrm{c}, \mathrm{f}(\mathrm{c})=\mathrm{d}, \mathrm{f}(\mathrm{d})=\mathrm{a}$ in the above example. $\mathrm{f}$ is $\beta$-closed, but not pgrw-closed.

Example 3.22: To show that pgrw-closed map and semi-closed map are independent.

i) $\mathrm{X}=\{\mathrm{a}, \mathrm{b}, \mathrm{c}\}, \tau=\{\mathrm{X}, \phi,\{\mathrm{a}\}\}$ and $\mathrm{Y}=\{\mathrm{a}, \mathrm{b}, \mathrm{c}, \mathrm{d}\}, \sigma=\{\mathrm{Y}, \phi,\{\mathrm{a}\},\{\mathrm{b}\},\{\mathrm{a}, \mathrm{b}\},\{\mathrm{a}, \mathrm{b}, \mathrm{c}\}\}$

Pgrw-closed sets in $Y$ are $Y, \phi,\{c\},\{d\},\{b, c\},,\{c, d\},\{a, d\},\{b, d\},\{b, c, d\},\{a, c, d\},\{a, b, d\}$.

Semi-closed sets in $\mathrm{Y}$ are $\mathrm{Y}, \phi,\{\mathrm{a}\},\{\mathrm{b}\},\{\mathrm{c}\},\{\mathrm{d}\},\{\mathrm{b}, \mathrm{d}\},\{\mathrm{a}, \mathrm{c}\},\{\mathrm{b}, \mathrm{c}\},\{\mathrm{c}, \mathrm{d}\},\{\mathrm{a}, \mathrm{d}\},\{\mathrm{b}, \mathrm{c}, \mathrm{d}\},\{\mathrm{a}, \mathrm{c}, \mathrm{d}\}$.

A map $\mathrm{f}: \mathrm{X} \rightarrow \mathrm{Y}$ is defined by $\mathrm{f}(\mathrm{a})=\mathrm{b}, \mathrm{f}(\mathrm{b})=\mathrm{a}, \mathrm{f}(\mathrm{c})=\mathrm{d}$. $\mathrm{f}$ is pgrw-closed, but $\mathrm{f}$ is not semi-closed.

ii) A map $\mathrm{f}: \mathrm{X} \rightarrow \mathrm{Y}$ is defined by $\mathrm{f}(\mathrm{a})=\mathrm{d}, \mathrm{f}(\mathrm{b})=\mathrm{a}, \mathrm{f}(\mathrm{c})=\mathrm{a}$ in the above example. $\mathrm{f}$ is semi-closed, but not pgrwclosed. 
Theorem 3.23: If a map $\mathrm{f}:(\mathrm{X}, \tau) \rightarrow(\mathrm{Y}, \sigma)$ is pgrw-closed and $\mathrm{A}$ is a closed subset of $\mathrm{X}$, then $\mathrm{f}_{\mathrm{A}}:\left(\mathrm{A}, \tau_{\mathrm{A}}\right) \rightarrow(\mathrm{Y}, \sigma)$ is pgrw-closed.

Proof: $A$ is a closed set of $X$. Let $F$ be a closed set of $\left(A, \underline{\tau}_{A}\right)$. Then $F=A \cap E$ for some closed set $E$ of $(X, \tau)$ and so $F$ is a closed set of $(X, \tau)$. Since $f$ is a pgrw-closed map, $f(F)$ is pgrw-closed set in $(Y, \sigma)$. But for every $\mathrm{F}$ in $\mathrm{A}, \mathrm{f}_{\mathrm{A}}(\mathrm{F})=\mathrm{f}(\mathrm{F})$ and $\therefore \mathrm{f}_{\mathrm{A}}:\left(\mathrm{A}, \tau_{\mathrm{A}}\right) \rightarrow(\mathrm{Y}, \sigma)$ is pgrw-closed.

Theorem 3.24: If a map $\mathrm{f}:(\mathrm{X}, \tau) \rightarrow(\mathrm{Y}, \sigma)$ is pgrw-closed, then $\operatorname{pgrwcl}(\mathrm{f}(\mathrm{A})) \subseteq \mathrm{f}(\mathrm{cl}(\mathrm{A}))$ for every subset $\mathrm{A}$ of X.

Proof: Suppose $\mathrm{f}:(\mathrm{X}, \tau) \rightarrow(\mathrm{Y}, \sigma)$ is a pgrw-closed map.Let $\mathrm{A} \subseteq \mathrm{X}$. As cl(A) is closed in $\mathrm{X}$ and $\mathrm{f}$ is pgrwclosed,f(cl(A)) is pgrw-closed inY . and so pgrwcl(f(cl(A))) $=\mathrm{f}(\operatorname{cl}(\mathrm{A})) \ldots \ldots .(1)[32]$. Next $\mathrm{A} \subseteq \operatorname{cl}(\mathrm{A}) . \therefore \mathrm{f}(\mathrm{A}) \subseteq$ $\mathrm{f}(\mathrm{cl}(\mathrm{A})) . \quad \therefore \operatorname{pgrwcl}(\mathrm{f}(\mathrm{A})) \subseteq \operatorname{pgrwcl}(\mathrm{f}(\mathrm{cl}(\mathrm{A}))) \rightarrow(\mathrm{ii})[32]$.

From (i) and (ii), pgrw-cl(f(A)) $\subseteq \mathrm{f}(\mathrm{cl}(\mathrm{A})) \forall$ subset $\mathrm{A}$ of $(\mathrm{X}, \tau)$.

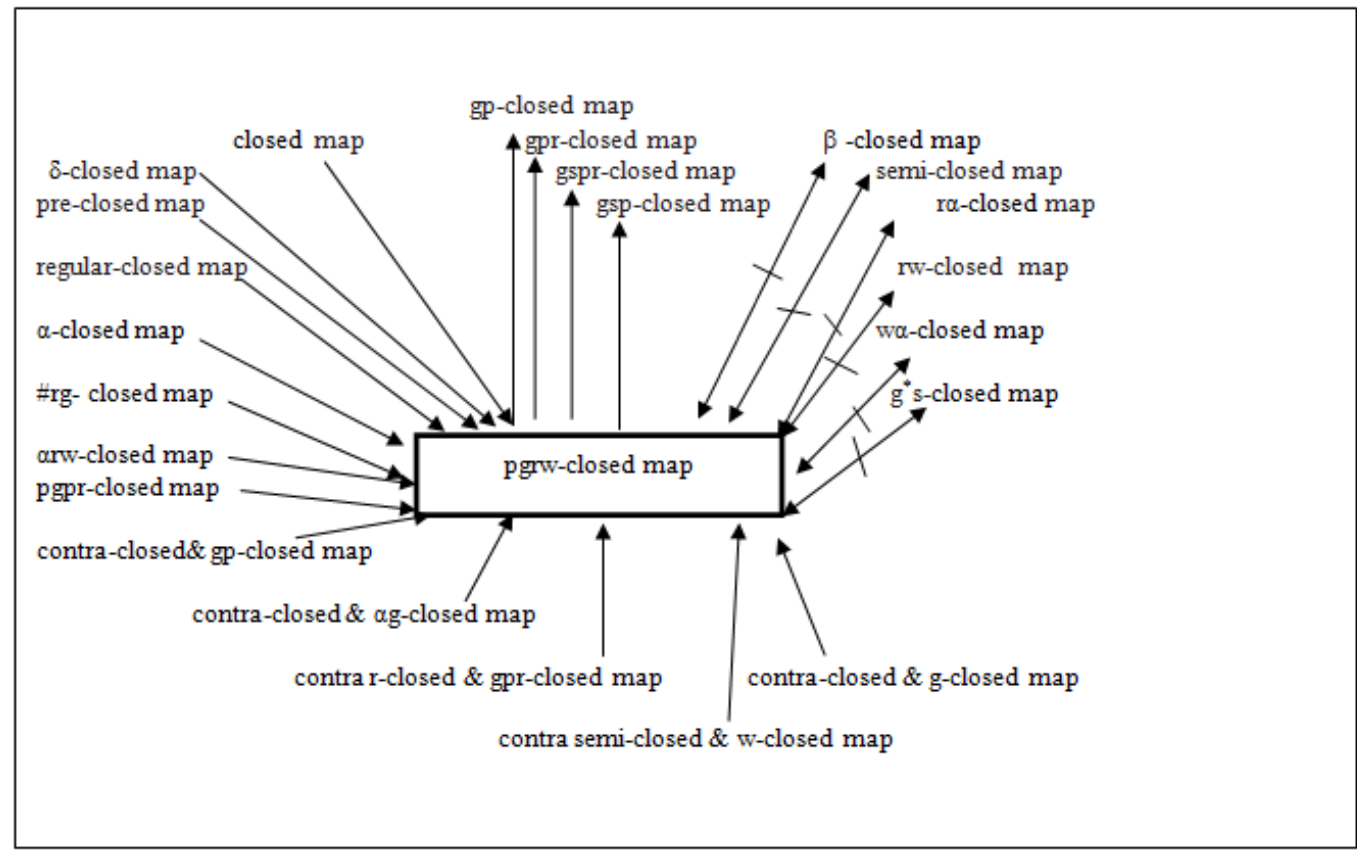

In the above diagram,

$\mathrm{A} \longrightarrow \mathrm{B}$ means'If A, then B.'

$\mathrm{A} \longleftrightarrow$ B means 'A and B are independent.'

Theorem 3.25: If a map $\mathrm{f}:(\mathrm{X}, \tau) \rightarrow(\mathrm{Y}, \sigma)$ is such that $\operatorname{pcl}(\mathrm{f}(\mathrm{A}))=\operatorname{pgrwcl}(\mathrm{f}(\mathrm{A})) \subseteq \mathrm{f}(\mathrm{cl}(\mathrm{A})) \forall \mathrm{A}$ in $\mathrm{X}$, then $\mathrm{f}$ is a pgrw-closed map.

Proof: Hypothesis: $\mathrm{f}:(\mathrm{X}, \tau) \rightarrow(\mathrm{Y}, \sigma)$ is a map such that $\operatorname{pcl}(\mathrm{f}(\mathrm{A}))=\operatorname{pgrwcl}(\mathrm{f}(\mathrm{A})) \subseteq \mathrm{f}(\mathrm{cl}(\mathrm{A})) \forall \mathrm{A}$ in $\mathrm{X}$. A is a closed subset of $(X, \tau)$.

$\Rightarrow \mathrm{A}=\mathrm{cl}(\mathrm{A}) \Rightarrow \mathrm{f}(\mathrm{A})=\mathrm{f}(\mathrm{cl}(\mathrm{A}))$.

$\Rightarrow \operatorname{pgrwcl}(\mathrm{f}(\mathrm{A})) \subseteq \mathrm{f}(\mathrm{A})$, by the hypothesis $\operatorname{pgrwcl}(\mathrm{f}(\mathrm{A})) \subseteq \mathrm{f}(\mathrm{cl}(\mathrm{A})) \forall \mathrm{A}$ in $\mathrm{X}$.

$\Rightarrow \mathrm{f}(\mathrm{A})=\operatorname{pgrwcl}(\mathrm{f}(\mathrm{A}))$ because $\mathrm{f}(\mathrm{A}) \subseteq \operatorname{pgrwcl}(\mathrm{f}(\mathrm{A})) \forall \mathrm{A}$ in $\mathrm{X}$.

$=\operatorname{pcl}(\mathrm{f}(\mathrm{A}))$ by hypothesis. $\Rightarrow \mathrm{f}(\mathrm{A})$ is pre-closed.

$\Rightarrow \mathrm{f}(\mathrm{A})$ is pgrw-closed in (Y, $\sigma)$. Thus $\forall$ closed set $\mathrm{A}$ in $\mathrm{Xf}(\mathrm{A})$ is pgrw-closed in $(Y, \sigma)$.

Hence $\mathrm{f}$ is a pgrw-closed map.

Theorem 3.26:A map $\mathrm{f}:(\mathrm{X}, \tau) \rightarrow(\mathrm{Y}, \sigma)$ is pgrw-closed if and only if $\forall$ subset $\mathrm{S}$ of $(\mathrm{Y}, \sigma)$ and for every open set $\mathrm{U}$ containing $\mathrm{f}^{-1}(\mathrm{~S})$ in $\mathrm{X}$, there is a pgrw-open set $\mathrm{V}$ of $(\mathrm{Y}, \sigma) \operatorname{such}$ that $\mathrm{S} \subseteq \mathrm{V}$ and $\mathrm{f}^{-1}(\mathrm{~V}) \subseteq \mathrm{U}$.

Proof:i) $f:(X, \tau) \rightarrow(Y, \sigma)$ is a map, $S$ is subset of $Y$ and $f^{-1}(S) \subseteq U$, a subset of $X . \Rightarrow S \cap f(X-U)=\phi \Rightarrow S \subseteq Y$ $\mathrm{f}(\mathrm{X}-\mathrm{U})$.

ii)f $:(X, \tau) \rightarrow(Y, \sigma)$ is a pgrw-closed map and $U$ is an open set in $X$.

$\Rightarrow \mathrm{f}(\mathrm{X}-\mathrm{U})$ is a pgrw-closed set in $\mathrm{Y}$.

$\Rightarrow \mathrm{Y}-\mathrm{f}(\mathrm{X}-\mathrm{U})=\mathrm{V}$ (say) is a pgrw-open set in $\mathrm{Y}$.

$\Rightarrow \mathrm{f}^{-1}(\mathrm{~V})=\mathrm{X}-\mathrm{f}^{-1}(\mathrm{f}(\mathrm{X}-\mathrm{U})) \subseteq \mathrm{X}-(\mathrm{X}-\mathrm{U})=\mathrm{U}$.

So from (i) and (ii) if $\mathrm{f:}(\mathrm{X}, \tau) \rightarrow(\mathrm{Y}, \sigma)$ is a pgrw-closed map, then $\forall \mathrm{S} \subseteq \mathrm{Y}$ and $\forall$ open set $\mathrm{U}$ containing $\mathrm{f}^{-1}(\mathrm{~S})$ in $\mathrm{X} \exists$ a pgrw-open set $\mathrm{V}=\mathrm{Y}-\mathrm{f}(\mathrm{X}-\mathrm{U})$ such that $\mathrm{S} \subseteq \mathrm{V}$ and $\mathrm{f}^{-1}(\mathrm{~V}) \subseteq \mathrm{U}$.

Conversely 
Suppose $\mathrm{f}:(\mathrm{X}, \tau) \rightarrow(\mathrm{Y}, \sigma)$ is a map such that $\forall \mathrm{S} \subseteq \mathrm{Y}$ and $\forall$ open set $\mathrm{U}$ containing $\mathrm{f}^{-1}(\mathrm{~S})$ in $\mathrm{X}$, there exists a pgrw-open set $\mathrm{V}$ in $\mathrm{Y}$ such that $\mathrm{S} \subseteq \mathrm{V}$ and $\mathrm{f}^{-1}(\mathrm{~V}) \subseteq \mathrm{U}$.

$\forall \mathrm{F} \subseteq \mathrm{X}$ and for any map $\mathrm{f}: \mathrm{X} \rightarrow \mathrm{Y}, \mathrm{f}^{-1}\left((\mathrm{f}(\mathrm{F}))^{\mathrm{c}}\right) \subseteq \mathrm{F}^{\mathrm{c}}$. If $\mathrm{F}$ is a closed subset of $\mathrm{X}$, then $\mathrm{F}^{\mathrm{c}}$ is open in $\mathrm{X}$. Take $\mathrm{S}=(\mathrm{f}(\mathrm{F}))^{\mathrm{c}}$ and $\mathrm{U}=\mathrm{F}^{\mathrm{c}}$. Then by the hypothesis $\exists$ a pgrw-open set $\mathrm{V}$ in $\mathrm{Y}$ such that $\mathrm{S} \subseteq \mathrm{V}$ and $\mathrm{f}^{-1}(\mathrm{~V}) \subseteq \mathrm{U}$. i.e. $(\mathrm{f}(\mathrm{F}))^{\mathrm{c}} \subseteq \mathrm{V}$ and $\mathrm{f}^{-1}(\mathrm{~V}) \subseteq \mathrm{F}^{\mathrm{c}} \Rightarrow \mathrm{V}^{\mathrm{c}} \subseteq \mathrm{f}(\mathrm{F})$ and $\mathrm{F} \subseteq\left(\mathrm{f}^{-1}(\mathrm{~V})\right)^{\mathrm{c}}$

$\Rightarrow \mathrm{V}^{\mathrm{c}} \subseteq \mathrm{f}(\mathrm{F})$ and $\mathrm{f}(\mathrm{F}) \subseteq \mathrm{f}\left(\left(\mathrm{f}^{-1}(\mathrm{~V})\right)^{\mathrm{c}}\right) \subseteq \mathrm{V}^{\mathrm{c}} \Rightarrow \mathrm{V}^{\mathrm{c}} \subseteq \mathrm{f}(\mathrm{F})$ and $\mathrm{f}(\mathrm{F}) \subseteq \mathrm{V}^{\mathrm{c}} \Rightarrow \mathrm{V}^{\mathrm{c}}=\mathrm{f}(\mathrm{F})$

As $V$ is pgrw-open, $V^{c}$ is pgrw-closed in $Y$.i.e. $f(F)$ is pgrw-closed in $Y$. Thus $\forall$ closed set $F$ in $X, f(F)$ is pgrwclosed in $\mathrm{Y}$. Hence $\mathrm{f}:(\mathrm{X}, \tau) \rightarrow(\mathrm{Y}, \sigma)$ is a pgrw-closed map.

Theorem 3.27:If $\mathrm{f:}(\mathrm{X}, \tau) \rightarrow(\mathrm{Y}, \sigma)$ is a surjective, continuous, pgrw-closed and open map and $\mathrm{cl}(\mathrm{F})=\mathrm{F}, \forall$ pgrw-closed set $\mathrm{F}$ in $\mathrm{Y}$ where $\mathrm{X}$ is regular, then $\mathrm{Y}$ is regular.

Proof:Let $U$ be an open set in $Y$ and $y \in U$.

$\mathrm{f}$ is surjective. $\therefore \exists$ a point $\mathrm{x}$ in $\mathrm{f}^{-1}(\mathrm{U})$ such that $\mathrm{f}(\mathrm{x})=\mathrm{y}$.

$\mathrm{f}$ is continuous and $\mathrm{U}$ is open in $\mathrm{Y} . \therefore \mathrm{f}^{-1}(\mathrm{U})$ is open in $\mathrm{X} . \mathrm{X}$ is a regular space. $\therefore \exists$ an open set $\mathrm{V}$ in $\mathrm{X}$ such that $\mathrm{x} \in \mathrm{V} \subseteq \mathrm{cl}(\mathrm{V}) \subseteq \mathrm{f}^{-1}(\mathrm{U})$ and so $\mathrm{f}(\mathrm{x}) \in \mathrm{f}(\mathrm{V}) \subseteq \mathrm{f}\left(\mathrm{cl}(\mathrm{V}) \subseteq \mathrm{f}\left(\mathrm{f}^{-1}(\mathrm{U})\right)\right.$.

i.e. $\mathrm{y} \in \mathrm{f}(\mathrm{V}) \subseteq \mathrm{f}(\mathrm{cl}(\mathrm{V})) \subseteq \mathrm{U}$.

$\mathrm{f}$ is a pgrw-closed map and $\mathrm{cl}(\mathrm{V})$ is closed in $\mathrm{X}$. $\quad \therefore \mathrm{f}(\mathrm{cl}(\mathrm{V}))$ is pgrw-closed in $\mathrm{Y}$ and so by the hypothesis $\operatorname{cl}(\mathrm{f}(\mathrm{cl}(\mathrm{V})))=\mathrm{f}(\mathrm{cl}(\mathrm{V}) \ldots \ldots \ldots$ (ii)

Also $\mathrm{V} \subseteq \mathrm{cl}(\mathrm{V}) \Rightarrow \mathrm{f}(\mathrm{V}) \subseteq \mathrm{f}(\mathrm{cl}(\mathrm{V})) \Rightarrow \operatorname{cl}(\mathrm{f}(\mathrm{V}) \subseteq \operatorname{cl}(\mathrm{f}(\mathrm{cl}(\mathrm{V})))=\mathrm{f}(\mathrm{cl}(\mathrm{V})$

From (i), (ii) and (iii) we have $\mathrm{y} \epsilon \mathrm{f}(\mathrm{V}) \subseteq \mathrm{cl}(\mathrm{f}(\mathrm{V}) \subseteq \mathrm{U}$. $\mathrm{V}$ is open in $\mathrm{X}$ and $\mathrm{f}$ is an open map. $\therefore \mathrm{f}(\mathrm{V})$ is open in $\mathrm{Y}$. Thus $\forall$ open set $\mathrm{U}$ in $\mathrm{Y}$ and $\forall \mathrm{y} \epsilon \mathrm{U}, \exists$ an open set $\mathrm{f}(\mathrm{V})$ in $\mathrm{Y}$ such that

$\mathrm{y} \in \mathrm{f}(\mathrm{V}) \subseteq \mathrm{cl}(\mathrm{f}(\mathrm{V})) \subseteq \mathrm{U}$. Hence $\mathrm{Y}$ is a regular space.

Theorem 3.28: If $\mathrm{f}:(\mathrm{X}, \tau) \rightarrow(\mathrm{Y}, \sigma)$ is a continuous, pgrw-closed and bijective map and $\mathrm{X}$, a normal space, then for every pair of disjoint closed sets $\mathrm{A}$ and $\mathrm{B}$ in $(\mathrm{Y}, \sigma)$, there exist disjoint pgrw-open sets $\mathrm{C}$ and $\mathrm{D}$ in $\mathrm{Y}$ such that $\mathrm{A} \subseteq \operatorname{pint}(\mathrm{C})$ and $\mathrm{B} \subseteq \operatorname{pint}(\mathrm{D})$.

Proof: $A$ and $B$ be disjoint closed sets in $(Y, \sigma)$. If $f$ is continuous, then $\mathrm{f}^{-1}(A)$ and $\mathrm{f}^{-1}(\mathrm{~B})$ are disjoint closed sets of $(X, \tau)$. If $X$ is a normal space, then $\exists$ disjoint-open sets $U$ and $V$ in $X$ such that $f^{-1}(A) \subseteq U$ and $f^{-1}(B) \subseteq V$. Now $\mathrm{f}$ is a pgrw-closed map, $\mathrm{A} \subseteq \mathrm{Y}$ and $\mathrm{U}$, an open set containing $\mathrm{f}^{-1}(\mathrm{~A})$ in $\mathrm{X} . \Rightarrow \exists$ a pgrw-open set $\mathrm{C}$ in $\mathrm{Y}$ such that $\mathrm{A} \subseteq \mathrm{C}$ and $\mathrm{f}^{-1}(\mathrm{C}) \subseteq \mathrm{U}$ by theorem 3.26. Similarly for $\mathrm{B}$ and $\mathrm{V} \exists$ a pgrw-open set $\mathrm{D}$ in $\mathrm{Y}$ such that $\mathrm{B}$ $\subseteq \mathrm{D}$ and $\mathrm{f}^{-1}(\mathrm{D}) \subseteq \mathrm{V}$.

To prove $\mathrm{C} \cap \mathrm{D}=\phi$ : If $\mathrm{f}$ is an injective map, then $\mathrm{U} \cap \mathrm{V}=\phi . \quad \Rightarrow \mathrm{f}(\mathrm{U}) \cap \mathrm{f}(\mathrm{V})=\phi . \quad$ And $\mathrm{f}^{-1}(\mathrm{C}) \subseteq \mathrm{U}$ and $\mathrm{f}^{-1}(\mathrm{D}) \subseteq \mathrm{V} . \Rightarrow \mathrm{f}\left(\mathrm{f}^{-1}(\mathrm{C})\right) \subseteq \mathrm{f}(\mathrm{U})$ and $\mathrm{f}\left(\mathrm{f}^{-1}(\mathrm{D})\right) \subseteq \mathrm{f}(\mathrm{V})$.

$\Rightarrow \mathrm{C} \subseteq \mathrm{f}(\mathrm{U})$ and $\mathrm{D} \subseteq \mathrm{f}(\mathrm{V})$, $\mathrm{f}$ being surjective $\mathrm{f}\left(\mathrm{f}^{-1}(\mathrm{G})\right)=\mathrm{G}, \forall \mathrm{G}$ in $\mathrm{Y}$.

$\Rightarrow \mathrm{C} \cap \mathrm{D} \subseteq \mathrm{f}(\mathrm{U}) \cap \mathrm{f}(\mathrm{V})=\phi \Rightarrow \mathrm{C} \cap \mathrm{D}=\phi$.

Next $\mathrm{A}$ is a closed set in $\mathrm{Y}$ and $\mathrm{A} \subseteq \mathrm{C}$, a pgrw-open set.

$\Rightarrow \mathrm{A}$ is rw-closed and $\mathrm{A} \subseteq \mathrm{C}$, a pgrw-open set

$\Rightarrow \mathrm{A} \subseteq \operatorname{pint}(\mathrm{C}) \quad[32(4.4)]$. Similarly $\mathrm{B} \subseteq \operatorname{pint}(\mathrm{D})$.

\section{Composition Of Maps}

Remark 4.1: The composition of two pgrw-closed maps need not be a pgrw-closed map.

Example 4.2: $X=\{a, b, c\}, \tau=\{X, \phi,\{a\},\{a, b\}\}$. The closed sets in $X$ are $X, \phi,\{b, c\},\{c\}$.

$\mathrm{Y}=\{\mathrm{a}, \mathrm{b}, \mathrm{c}\}, \sigma=\{\mathrm{Y}, \phi,\{\mathrm{a}\}\}$, the closed sets in $\mathrm{Y}$ are $\mathrm{Y}, \phi,\{\mathrm{b}, \mathrm{c}\}$. pgrw-closed sets in $\mathrm{Y}$ are $\mathrm{Y}, \phi,\{\mathrm{b}\},\{\mathrm{c}\},\{\mathrm{b}, \mathrm{c}\}$. $Z=\{a, b, c\}, \eta=\{Z, \phi,\{a\},\{c\},\{a, c\}\}$. pgrw-closed sets in $Z$ are $Z, \phi,\{b\},\{a, b\},\{b, c\}$. Let $f:(X, \tau) \rightarrow(Y, \sigma)$ and $g:$

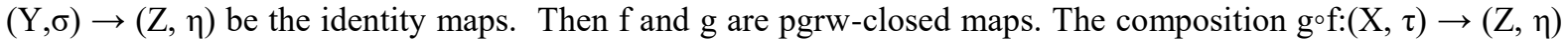
is not pgrw-closed, because $\{c\}$ is closed in $X$ and $\operatorname{g} \circ(\{c\})=g(f\{c\})=g(\{c\})=\{c\}$ is not pgrw-closed in $Z$.

Theorem 4.3: If $\mathrm{f}:(\mathrm{X}, \tau) \rightarrow(\mathrm{Y}, \sigma)$ is a closed map and $\mathrm{g}:(\mathrm{Y}, \sigma) \rightarrow(\mathrm{Z}, \eta)$ is a pgrw-closed map, then the composition g॰f: $(X, \tau) \rightarrow(Z, \eta)$ is a pgrw-closed map.

Proof: $f:(X, \tau) \rightarrow(Y, \sigma)$ is a closed map and $g:(Y, \sigma) \rightarrow(Z, \eta)$ is a pgrw-closed map.

$\Rightarrow \forall$ closed set $F$ in $X f(F)$ is closed set in $(Y, \sigma)$ and $g(f(F))$ is a pgrw-closed set in $(Z, \eta)$.

$\Rightarrow \forall$ closed set $F$ in $X$ gof $(F)=g(f(F))$ is a pgrw-closed set in $(Z, \eta)$.

$\Rightarrow \mathrm{g} \circ \mathrm{f}(\mathrm{X}, \tau) \rightarrow(\mathrm{Z}, \eta)$ is a pgrw-closed map.

Remark 4.4: If $\mathrm{f}:(\mathrm{X}, \tau) \rightarrow(\mathrm{Y}, \sigma)$ is a pgrw-closed map and $\mathrm{g}:(\mathrm{Y}, \sigma) \rightarrow(\mathrm{Z}, \eta)$ is a closed map, then the composition gof need not be a pgrw-closed map.

Example 4.5: $\mathrm{X}=\{\mathrm{a}, \mathrm{b}, \mathrm{c}\}, \tau=\{\mathrm{X}, \phi,\{\mathrm{a}\},\{\mathrm{b}\},\{\mathrm{a}, \mathrm{b}\}\}, \quad \mathrm{Y}=\{\mathrm{a}, \mathrm{b}, \mathrm{c}\}, \sigma=\{\mathrm{Y}, \phi,\{\mathrm{a}\},\{\mathrm{b}, \mathrm{c}\}\}, \mathrm{Z}=\{\mathrm{a}, \mathrm{b}, \mathrm{c}\}, \eta=\{\mathrm{Z}, \phi$, $\{b\},\{c\},\{b, c\}\}$. The closed sets in $X$ are $X, \phi,\{c\},\{a, c\},\{b, c\}$. Closed sets in $Y$ are $Y, \phi,\{b, c\},\{a\}$. pgrwclosed sets in $\mathrm{Y}$ are all subsets of $\mathrm{Y}$. The closed sets in $\mathrm{Z}$ are $\mathrm{Z}, \phi,\{\mathrm{a}\},\{\mathrm{a}, \mathrm{b}\},\{\mathrm{a}, \mathrm{c}\}$. pgrw-closed sets in $\mathrm{Z}$ are $\mathrm{Z}$, $\phi,\{a\},\{a, b\},\{a, c\}$. Let $f: X \rightarrow Y$ be the identity map. Then $f$ is a pgrw-closed map. A map $g: Y \rightarrow Z$ is defined 


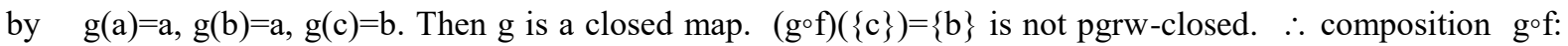
$(\mathrm{X}, \tau) \rightarrow(\mathrm{Z}, \eta)$ is not a pgrw-closed map.

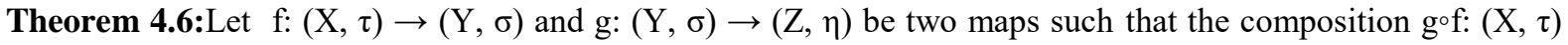
$\rightarrow(Z, \eta)$ is a pgrw-closed map. Then the following statements are true.

(i) If $\mathrm{f}$ is continuous and surjective, then $\mathrm{g}$ is pgrw-closed.

(ii) If $\mathrm{g}$ is pgrw-irresolute[35] and injective, then $\mathrm{f}$ is pgrw-closed.

(iii) If $g$ is strongly pgrw-continuous and injective, then $\mathrm{f}$ is pgrw-closed.

Proof:(i) Let A be a closed set of Y. Since $f$ is continuous, $f^{-1}(A)$ is a closed set in $X$ and since gof is a pgrwclosed map $(g \circ f)\left(f^{-1}(A)\right)$ is pgrw-closed in $Z$. As $f$ is surjective $(g \circ f)\left(f^{-1}(A)=g(A)\right.$. So $g(A)$ is a pgrw-closed set in $\mathrm{Z}$. Therefore $\mathrm{g}$ is a pgrw-closed map.

(ii) Let $B$ be a closed set of $(X, \tau)$. Since $g \circ f$ is pgrw-closed, $(g \circ f)(B)$ is pgrw-closed in $(Z, \eta)$. Since $g$ is pgrwirresolute, $g^{-1}(g \circ f(B))$ is a pgrw-closed set in $(Y, \sigma)$. As $g$ is injective,

$\mathrm{g}^{-1}(\mathrm{~g} 0 \mathrm{f})(\mathrm{B})=\mathrm{f}(\mathrm{B}) . \quad \therefore \mathrm{f}(\mathrm{B})$ is pgrw-closed in $(\mathrm{Y}, \sigma) . \quad \therefore \mathrm{f}$ is a pgrw-closed map.

(iii) Let $C$ be a closed set of $(X, \tau)$. Since $g \circ f$ is pgrw-closed, $(g \circ f)(C)$ is pgrw-closed in

$(\mathrm{Z}, \eta)$. Since $\mathrm{g}$ is strongly pgrw-continous, $\mathrm{g}^{-1}((\mathrm{~g} \circ \mathrm{f})(\mathrm{C})$ is a closed set in $(\mathrm{Y}, \sigma)$. As $\mathrm{g}$ is injective, $\mathrm{g}$ ${ }^{1}(\operatorname{gof}(\mathrm{C}))=\mathrm{f}(\mathrm{C})$. So $\mathrm{f}(\mathrm{C})$ is a pgrw-closed set. $\therefore \mathrm{f}$ is a pgrw-closed map.

\section{Pgrw*-Closed Map}

Definition 5.1: A map f: $(\mathrm{X}, \tau) \rightarrow(\mathrm{Y}, \sigma)$ is said to be a pgrw*-closed map if $\forall$ pgrw-closed set A in $(\mathrm{X}, \tau)$ the image $\mathrm{f}(\mathrm{A})$ is pgrw-closed in $(\mathrm{Y}, \sigma)$.

Example 5.2: $X=\{a, b, c\}, \tau=\{X, \phi,\{a\},\{a, c\}\}$. pgrw-closed sets in $X$ are $X, \phi,\{b\},\{c\},\{b, c\} . Y=\{a, b, c\}, \sigma$ $=\{\mathrm{Y}, \phi,\{\mathrm{a}\},\{\mathrm{b}, \mathrm{c}\}\}$. pgrw-closed sets in $\mathrm{Y}$ are $\mathrm{Y}, \phi,\{\mathrm{a}\},\{\mathrm{b}\},\{\mathrm{c}\},\{\mathrm{a}, \mathrm{b}\},\{\mathrm{b}, \mathrm{c}\},\{\mathrm{a}, \mathrm{c}\} . \mathrm{A} \operatorname{map} \mathrm{f:}(\mathrm{X}, \tau) \rightarrow(\mathrm{Y}$, $\sigma)$ is defined by $f(a)=b, f(b)=c, f(c)=a$. Then $f$ is a pgrw*-closed map.

Theorem 5.3: Every pgrw*-closed map is a pgrw-closed map.

Proof: Let $\mathrm{f}:(\mathrm{X}, \tau) \rightarrow(\mathrm{Y}, \sigma)$ be a pgrw*-closed map. Let A be a closed set in X. Then A is pgrw-closed. As $\mathrm{f}$ is pgrw*-closed, $\mathrm{f}(\mathrm{A})$ is pgrw-closed in Y. Hence $\mathrm{f}$ is a pgrw-closed map.

The converse is not true.

Example 5.4: $\mathrm{X}=\{\mathrm{a}, \mathrm{b}, \mathrm{c}\}, \tau=\{\mathrm{X}, \phi,\{\mathrm{a}\}\} . \mathrm{Y}=\{\mathrm{a}, \mathrm{b}, \mathrm{c}\}, \sigma=\{\mathrm{Y}, \phi,\{\mathrm{a}\},\{\mathrm{b}\},\{\mathrm{a}, \mathrm{b}\}\}$.

Pgrw-closed sets in $\mathrm{X}$ are $\mathrm{X}, \phi,\{\mathrm{b}\},\{\mathrm{c}\},\{\mathrm{b}, \mathrm{c}\}$. pgrw-closed sets in $\mathrm{Y}$ are $\mathrm{Y}, \phi,\{\mathrm{c}\},\{\mathrm{b}, \mathrm{c}\},\{\mathrm{a}, \mathrm{c}\}$. A map f:(X, $\tau) \rightarrow(Y, \sigma)$ is defined by $f(a)=c, f(b)=c, f(c)=b$. $f$ is pgrw-closed, but not pgrw*-closed.

Theorem 5.5: If $\mathrm{f:}(\mathrm{X}, \tau) \rightarrow(\mathrm{Y}, \sigma)$ is a pgrw-closed map and $\mathrm{g}:(\mathrm{Y}, \sigma) \rightarrow(\mathrm{Z}, \eta)$ is a pgrw*-closed map, then the composition $\mathrm{g} \circ \mathrm{f}:(\mathrm{X}, \tau) \rightarrow(\mathrm{Z}, \eta)$ is pgrw-closed.

Proof: $f:(X, \tau) \rightarrow(Y, \sigma)$ is a pgrw-closed map and $g:(Y, \sigma) \rightarrow(Z, \eta)$ is a pgrw*-closed map.

$\Rightarrow \forall$ closed set $A$ in $X, f(A)$ is pgrw-closed in $Y$ and $g(f(A))$ is pgrw-closed in $Z$.

$\Rightarrow \forall$ closed set $A$ in $X, g \circ f(A)$ is pgrw-closed in $Z$.

$\Rightarrow \mathrm{g} \circ \mathrm{f}:(\mathrm{X}, \tau) \rightarrow(Z, \eta)$ is a pgrw-closed map.

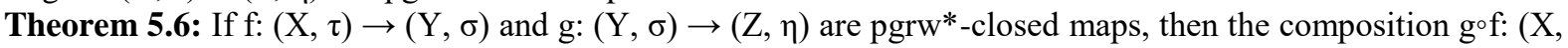
$\tau) \rightarrow(Z, \eta)$ is also pgrw*-closed.

Proof: $f:(X, \tau) \rightarrow(Y, \sigma)$ and $g:(Y, \sigma) \rightarrow(Z, \eta)$ are pgrw*-closed maps.

$\Rightarrow \forall$ pgrw-closed set $\mathrm{A}$ in $\mathrm{X}, \mathrm{f}(\mathrm{A})$ is pgrw-closed in $\mathrm{Y}$ and $\mathrm{g}(\mathrm{f}(\mathrm{A}))$ is pgrw-closed in $\mathrm{Z}$.

$\Rightarrow \forall$ pgrw- closed set A in $\mathrm{X}, \mathrm{g} \circ \mathrm{f}(\mathrm{A})$ is pgrw-closed in $\mathrm{Z}$.

$\Rightarrow \mathrm{g} \circ \mathrm{f}:(X, \tau) \rightarrow(Z, \eta)$ is a pgrw*-closed map.

\section{References}

[1]. Malghan S. R. (1982), Generalized Closed Maps, J Karnataka Univ.Sci., 27 : 82-88

[2]. Nagaveni N. (1999). Studies on Generalizations of Homeomorphisms in Topological Spaces, Ph.D. Thesis, Bharathiar University,Coimbatore,

[3]. Long ,Herington(1978)., Basic Properties of Regular Closed Functions, Rend. Cir. Mat. Palermo, 27, 20-28,

[4]. Gnanambal Y. (1997), On generalized pre regular closed sets in topological spaces, Indian J Pure. Appl. Math., 28(3):351-360.

[5]. S. S. Benchalli, R.S., Wali(2007), On rw-Closed sets is Topological Spaces, Bull, Malays, Math, Sci, Soc., 30, 99-110.

[6]. Levine N. (1963), Semi-open sets and semi-continuity in topological spaces, Amer. Math. Monthly, 70 36-41.

[7]. Mashhour, Abd. El-Monsef M.E(1982), S. N. El-Deeb, On pre-continuous and weak pre continuous mappings, Proc. Math. Phys. Soc. Egypt, 53:47-53.

[8]. Mashhour, Hasanein, S. N. El-Deeb(1983), Acta Mathematica Hungarica,41(3-4), 213-218 $\alpha$-Continuous and $\alpha$-open mappings

[9]. Abd El-Monsef M.E, El-Deeb S N, Mahmoud RA. (1983) $\beta$-open sets and $\beta$-continuous mappings, Bull. Fac. Sci.Assiut Univ; 12: 77-90.

[10]. Stone M.(1937), Application of the theory of Boolean rings to general topology, Trans. Amer. Math.Soc; 41:374-481.

[11]. Raja Mohammad Latif(2014), Characterizations of delta-open sets and mappings in topological spaces may 12,

[12]. Cameron D. E., (1978); Properties of s-closed spaces, Proc. Amer. Math. Soc. 72: 581-586.

[13]. Vadivel Vairamamanickam. (2009); rg $\alpha$-Closed sets \& rg $\alpha$-open sets in Topological Spaces, Int. J. of math. Analysis., 3(37):18031819

[14]. Levine N. (1970), Generalized closed sets in topology, Rend.Circ Mat. Palermo19(2):89-96. 
[15]. Palaniappan N. and K. C. Rao(1993), Regular generalized closed sets, Kyungpook, Math. J., 33(2) 211-219

[16]. Dontchev. J(1995), On generalizing semi-pre- open sets. Mem. Fac. Sci. Kochi Uni. Ser. A Math., 35-48.

[17]. Sundaram P., M. Sheik John(2000); On w-closed sets in topology, Acta Ciencia Indica 4:389-39

[18]. Anitha M. \& P. Thangavelu(2005), On pre generalized pre regular closed sets (pgpr) Acta Ciencia Indian, 31(4), 1035-1040.

[19]. Navalgi, A.S. Chandrashekharappa and S.V.Gurushantanavar(Jan.2012), Gspr-open functions in Toplogical Spaces. Int. J. of Mathematical Sciences \& Applications, 2(1), , pp. 231-237

[20]. Noiri, H. Maki and J. Umehara(1998), "Generalized Pre-closed Functions". Mem. Fac. Sci. Kochi.Univ. (Math)19, 13-20

[21]. Syed Ali Fathima and Mariasingam. M. (2012), "On \#RG-Continuous and \#RG-irresolute functions", Journal of Advanced Studies in Topology, 3(4), , 28-33

[22]. Pushpalatha(2011), g*s-Closed Sets in Topological Spaces, Int. J. Contemp. Math. Sciences, 6(19), , 917 - 929

[23]. H. Maki Devi R, Balachandran K. ,(1994); Associated topologies of generalized $\alpha$-closed sets and $\alpha$-generalized closed sets, Mem. Fac. Sci. Kochi Univ. Ser. A. Math15:51-63.

[24]. Benchalli S. S. ,Patil, P. G. (2010), Some New Continuous Maps in Topological Spaces, Journal of Advanced Studies in Topology, Vol. 1 Issue 2, p 16-21

[25]. Wali R.S., Prabhavati S Mandalageri(2015);. On $\alpha \mathrm{r} \omega$-closed and $\alpha \mathrm{r} \omega$-open maps inTopological Spaces, International Journal of Applied Research 1(11): 511-518.

[26]. Sen A.K. and P.Bhattacharya(1983),, On pre-closed mappings, Bull. Cal. Math. Soc.,85 409-412.

[27]. Biswas, N. (1970) On characterization of semi-continuous function, Atti. Accad. Naz. Lincei Rend. Cl. Sci. Fis. Mat.Natur., 48(8), 399-402.

[28]. Baker C. W. (1994) Contra open and Contra closed functions, Math. Sci; 17:413-415.

[29]. Balasubramanian, Sellamuthu M, Sandhya C, Aruna Swathi Vyjayanthi P (April 2013), Contra regular pre-open mappings, Indian Journal of Science, Volume 3, Number 6.

[30]. Navalagi(2002);. "On Semi-pre Continuous Functions and Properties of Generalized Semi-pre Closed in Topology”, Int J. Math Stat. 29(2):85-98.

[31]. Wali R.S. and Vijayakumari T. Chilakwad(2015),, On Pre Generalized Regular Weakly [pgrw]-Closed sets in a Topological Space, International Journal of Mathematical Archive-6(1), 76-85. 